Brit. J. industr. Med., 1956, 13, 114.

\title{
TWO CASES OF META-DINITROBENZENE POISONING WITH UNEQUAL CLINICAL RESPONSE
}

\author{
BY \\ TIHOMIL BERITIĆ \\ From the Institute of Industrial Hygiene, Zagreb, Yugoslavia
}

(RECEIVED FOR PUBLICATION NOVEMBER 9, 1955)

The toxicity of $m$-dinitrobenzene has been known for about 85 years (Starkow, 1871). The first clinical cases of poisoning to be reported in the literature were in workers engaged in the production or handling of the explosive roburite (Nieden, 1888; Ross, 1889 ; Prosser White, 1889 ; Röhl, 1890 ; Spurgin, 1891), or that of aniline (Schröder and Strassmann, 1891), or were due to other occupational hazards (Huber, 1891). Numerous cases of industrial poisoning have been reported since then (von Oettingen, 1941). They were also mostly due to exposure in the manufacture of explosives, especially in the first world war. Cases of poisoning among munition workers were again recorded during and after the second world war (Rejsek, 1944 ; Glahn and Schack-Schou, 1947). Owing to modern improvements in hygienic conditions, however, cases of poisoning in industry seem now to be seldom encountered.

Considered retrospectively, the characteristic clinical manifestations of $m$-dinitrobenzene poisoning were already well recognized by the early authors. The most comprehensive clinical descriptions and a review of the first reports were given by Koelsch (1917). Since these early descriptions little has been added to the symptomatology of intoxication by the subsequent clinical reports. Recent experimental investigations on $m$-dinitrobenzene poisoning in Germany (Kunz, 1942 ; Kiese, 1949 ; Kiese and Siems, 1949 ; Cammerer, Kiese, and Tauschwitz, 1949 ; Gaede and Kiese, 1949) are also in agreement with the clinical observations. Thus both from the study of cases of $m$-dinitrobenzene poisoning in human beings and from experimental work on animals the most toxic effects may be summarized as follows : (1) effects on the blood, (2) effects on the liver, and (3) effects on the central nervous system.

It is well known that the toxic effects of aromatic nitro compounds vary with the intensity and length of the exposure and, according to Koelsch (1954), with the individual susceptibility in particular.
Regarding the toxicity of $m$-dinitrobenzene, Monks as early as 1902 points out that " there seems to be in some people a well marked idiosyncrasy to the poison, for all workmen are by no means equally affected ". A similar statement has also been made by Steiner (1918).

This paper gives an account of two patients who developed a somewhat different clinical picture of $m$-dinitrobenzene poisoning although working under exactly identical conditions and apparently exposed to the same extent to the toxic action of the poison.

\section{Process and Hazards}

The two patients were female process workers employed by a chemical firm and engaged in the manufacture of dinitrobenzene which was occasional and on a small scale. $m$-Dinitrobenzene was obtained by the classical method, i.e., by nitration of mononitrobenzene using the so-called nitration mixture (sulphuric and nitric acids). In this process the crude nitration product is washed several times with hot water. After being sufficiently freed from acids the technical product is submitted to recrystallization by dissolving it in boiling $96 \%$ ethyl alcohol and refluxing. After the addition of active charcoal for decoloration the mixture is filtered through canvas into a container. After separation of crystals the alcohol is removed by filtration through a Büchner funnel.

Occupational hazards which may arise during the synthesis of $m$-dinitrobenzene are: (1) handling the technical product before and after recrystallization (weighing, emptying the funnel), and (2) exposure to $m$-dinitrobenzene vapours during the filtration through the canvas filter. Since, however, $m$-dinitrobenzene boils at $297^{\circ} \mathrm{C}$. the actual hazard of vapours at the temperature of filtration does not seem to be probable.

The workers were provided with protective gloves which, however, they did not wear at all, although warned against the danger of handling the substance with bare hands. The processes of nitrating mononitrobenzene and of washing and drying the technical product were carried out under an exhaust hood, while the filtration of the alcoholic solution of $m$-dinitrobenzene was performed in the open. 
The nature of the work makes it difficult accurately to define the degree of exposure for each individual affected. There is no evidence, however, that one of them was more exposed to $m$-dinitrobenzene than the other: the length and the periods of exposure as well as the kind of work performed were equal.

\section{Case Histories}

Case 1.-A woman, aged 22, was admitted to the Institute's Department for Occupational Diseases on October 28, 1954, complaining of severe headache, abdominal pain, and nausea. There was a two-day history of loss of appetite, headaches, weakness, and sweating. In spite of these symptoms she continued to work, having been engaged in the preparation of dinitrobenzene since October 20. On the day of admission, while at the ordinary course of her work, she developed abdominal pain accompanied by nausea and dizziness. A friend drew her attention to the appearance of her lips which became "black-blue". She reported to the ambulance room where the administration of oxygen was started but was soon discontinued because she became increasingly dyspnoeic and dizzy, and she was transferred to the hospital by ambulance.

On examination she was found to be of a normal physique but pale with a marked cyanosis of the lips, oral mucosa, conjunctivae, ears, and finger tips. The skin of the palms and palmar aspect of the fingers was thick and yellow-brown. The colour of her finger nails was reddish-brown. The pulse rate was 98 per minute, and temperature $37 \cdot 4^{\circ} \mathrm{C}$. The blood pressure was $105,55 \mathrm{~mm}$. $\mathrm{Hg}$. The respiratory rate was slightly raised and the patient complained of air hunger. There was abdominal tenderness, especially marked along the right costal margin. The liver was palpable and very tender. No abnormality was detected in the nervous system.

Laboratory Investigations. - The erythrocyte sedimentation rate was $20 \mathrm{~mm}$. in one hour and $35 \mathrm{~mm}$. in two hours (Westergren). Haemoglobin was 63\% (Sahli). A blood count gave 3.54 millions per c.mm. red cells and 6,700 per c.mm. white cells with a normal differential count. Reticulocytes were $1.8 \%$ and Heinz bodies were not present. An osmotic fragility test was normal. The serum bilirubin was slightly raised to $1.66 \mathrm{mg}$. per $100 \mathrm{ml}$. (normal range up to $1 \mathrm{mg}$. per $100 \mathrm{ml}$.), the indirect van den Bergh test gave $0.73 \mathrm{mg}$. per $100 \mathrm{ml}$., thymol turbidity 4 units, and alkaline phosphatase 3.6 Bodansky units. The blood urea, serum iron, and fasting blood sugar levels were within normal limits. The concentration of methaemoglobin determined spectrophotometrically by the method of Heilmeyer (1943) was found to be $28 \%$ of total haemoglobin. No other pathological blood pigment could be detected spectroscopically. Routine examination of the urine for albumin, sugar, urobilinogen bilirubin, and blood revealed no abnormality. The excretion of ether-soluble porphyrins in the urine was $75 \mu \mathrm{g}$ per 24 hours.

Progress.-Ascorbic acid (1 g.) was given intravenously on admission after a blood sample for estimation of methaemoglobin had been taken. She continued to experience nausea for two hours and complained of epigastric pain. Later in the evening she was still cyanosed and was again given ascorbic acid (1 g.) intravenously. Throughout the second day she was only slightly cyanotic and her condition much improved. Nevertheless, the liver was found to be even more enlarged, two fingerbreadths below the costal margin. The temperature was 37.4 to $37.7^{\circ} \mathrm{C}$. and the blood pressure $110 / 70$. For the next eight days the liver was still enlarged and tender. She was on a high-carbohydrate, high-protein, and low-fat diet. During her stay in hospital the liver function tests were again performed but revealed no abnormality. The subsequent serial red blood cell and reticulocyte counts together with haemoglobin and methaemoglobin determinations are shown in Fig. 1. Heinz bodies were absent throughout.

She was discharged from hospitai on November 12 as an out-patient. When seen on November 30 she was clinically well. The liver was neither palpable nor tender. The blood picture and the liver function tests were normal.

Case 2.-A woman, aged 25, was admitted to the same Department two hours after the admission of her fellow worker, Case 1, because the suspicion of a similar poisoning had been aroused. She was engaged in the same work preparing $m$-dinitrobenzene. Three days before admission she felt sick, with general weakness, loss of appetite, ease of fatigue, and " nervousness". She did not give up her work, however, hoping that she would soon be better. During these three days she had also noticed that her lips were blue but the colour was never so deep as that in Case 1 on the day of the latter's admission. She had no abdominal pain, no nausea, no temperature, no headaches.

On admission she felt very weak and dizzy ; she was found to be of a rather poor physique, pale but only slightly cyanotic. The colour of the skin of the palms and fingers as well as of the finger-nails was yellowbrown. Her pulse rate was 76 per min., temperature $36.4^{\circ} \mathrm{C}$., and blood pressure $120 / 65 \mathrm{~mm}$. $\mathrm{Hg}$. There was no abdominal tenderness and the liver was not palpable.

Laboratory Investigations.-The E.S.R. was $7 \mathrm{~mm}$. in one hour, Hb $60 \%$ (Sahli), R.B.C.s 3.26 millions per c.mm., W.B.C.s 5,500 per c.mm. with a normal differential count, reticulocytes $4.7 \%$, and Heinz bodies $38 \%$. The serum bilirubin level was $1.74 \mathrm{mg}$. per $100 \mathrm{ml}$ and the indirect van den Bergh test gave a result of 0.57 $\mathrm{mg}$. per $100 \mathrm{ml}$. Other tests for liver function were normal. Serum iron was raised to $206 \mu \mathrm{g}$ per $100 \mathrm{ml}$. (normal range for female $80-130 \mu \mathrm{g}$. per $100 \mathrm{ml}$.). The blood urea and fasting blood sugar levels were normal. Methaemoglobin was $16 \%$ of total haemoglobin, but no other pathological pigment was found. An osmotic fragility test was within the normal range. The urine showed no proteinuria or other abnormality. Urinary excretion of ether-soluble porphyrins in the 24-hour specimen was $84 \mu \mathrm{g}$.

Progress.-The patient was treated with $1 \mathrm{~g}$. ascorbic acid daily. From the second day she was not cyanosed and complained only of the "nervousness" and fatigue. Because of a relatively high Heinz bodies count her red 
Case I

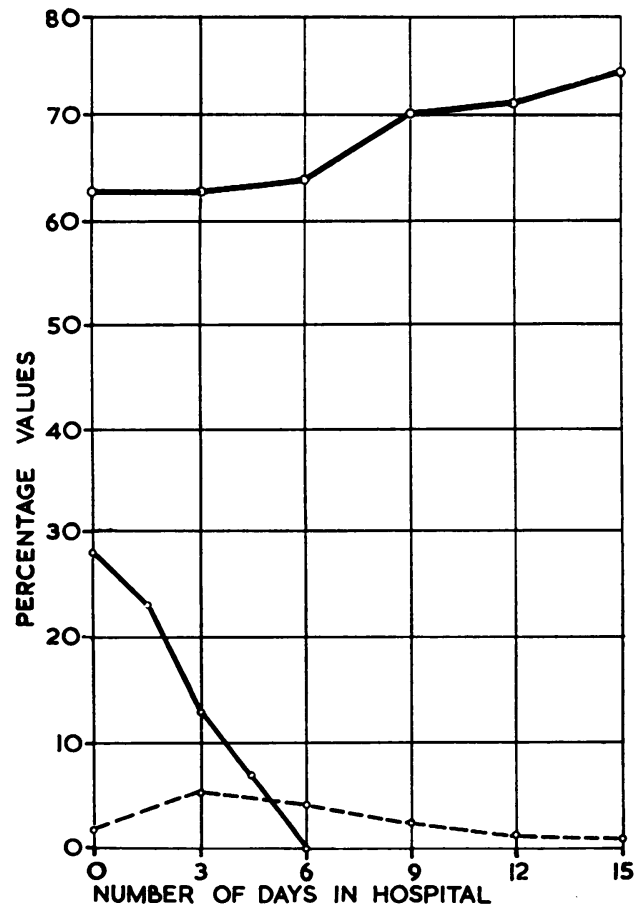

Case 2

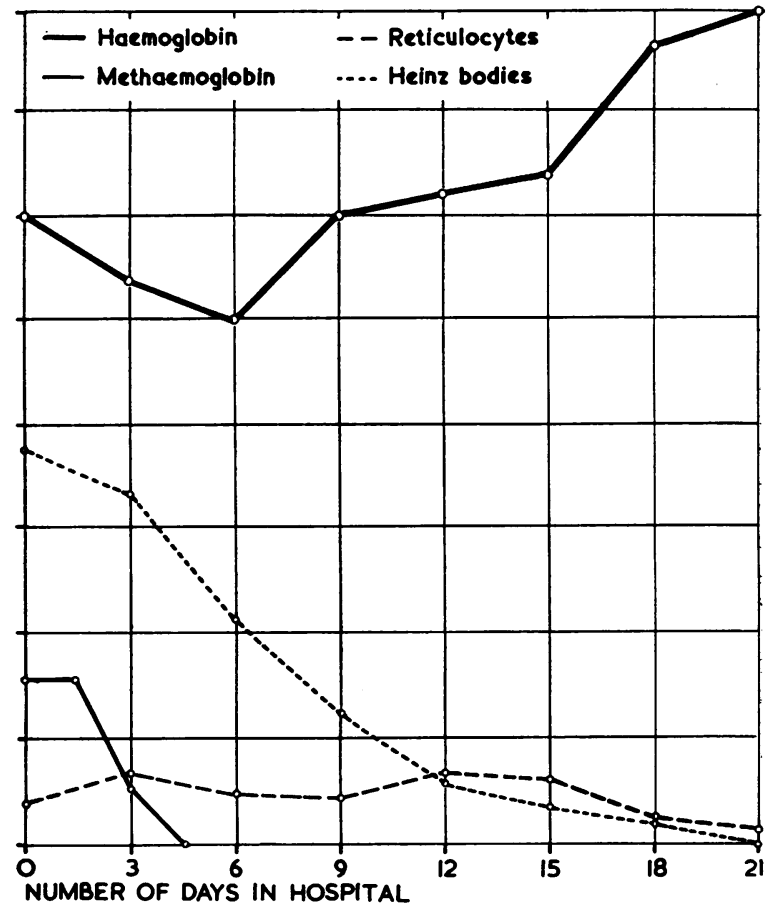

FIG. 1.-Graphs showing percentages of haemoglobin, methaemoglobin, reticulocytes, and Heinz bodies during the clinical course of intoxication.

blood picture was daily controlled : the course of the haematological investigations is shown in Fig. 1. Except for the haematological changes the patient showed no other clinical evidence of $m$-dinitrobenzene poisoning. On November 15 the serum iron was $87 \mu \mathrm{g}$. per $100 \mathrm{ml}$. She was discharged from hospital on November 19. When seen again she was clinically well. The only complaint was that of sleeplessness.

\section{Discussion}

The cases described here were women exposed to apparently identical risks of $m$-dinitrobenzene poisoning. After a week of exposure each developed symptoms and signs characteristic of the subacute type of $m$-dinitrobenzene poisoning, but there were certain differences in clinical features which should be particularly considered.

The most prominent effect of $m$-dinitrobenzene is its action on the blood pigment causing the formation of methaemoglobin. Accordingly methaemoglobinaemia is the commonest finding in most cases reported in the literature, although in a certain number of cases the authors failed to identify the pathological pigment (von Oettingen, 1941; Rejsek, 1944). Both cases recorded here suffered from methaemoglobinaemia ; its level was higher in
Case 1 and she also showed a higher degree of cyanosis.

The other product of the action of the poison upon the red cells is the formation of Heinz bodies in erythrocytes. Although much attention has been devoted to the blood changes in $m$-dinitrobenzene poisoning, many clinical observers made no mention of the incidence of Heinz bodies. Actually, as far as I can ascertain, only in four reports has the phenomenon of Heinz bodies been observed in connexion with clinical poisoning (Huber, 1891; Freifeld, Schilowa, and Ludwinowsky, 1937 ; Rejsek, 1944 ; Jung, 1946-47). In experimental poisoning, however, $m$-dinitrobenzene is shown to be a very good producer of Heinz bodies.

A relatively high number $(38 \%)$ of Heinz bodies (Fig. 1) was the prominent finding in Case 2 described here, whereas not a single erythrocyte with Heinz bodies could be detected in Case 1. In view of the concept that there exists a direct relation between the formation of methaemoglobin and Heinz bodies (Schilling, 1932 ; Moeschlin, 1942), it is noteworthy that the level of methaemoglobinaemia was even higher in Case 1 which had no Heinz bodies at all. In one case mentioned by Jung 


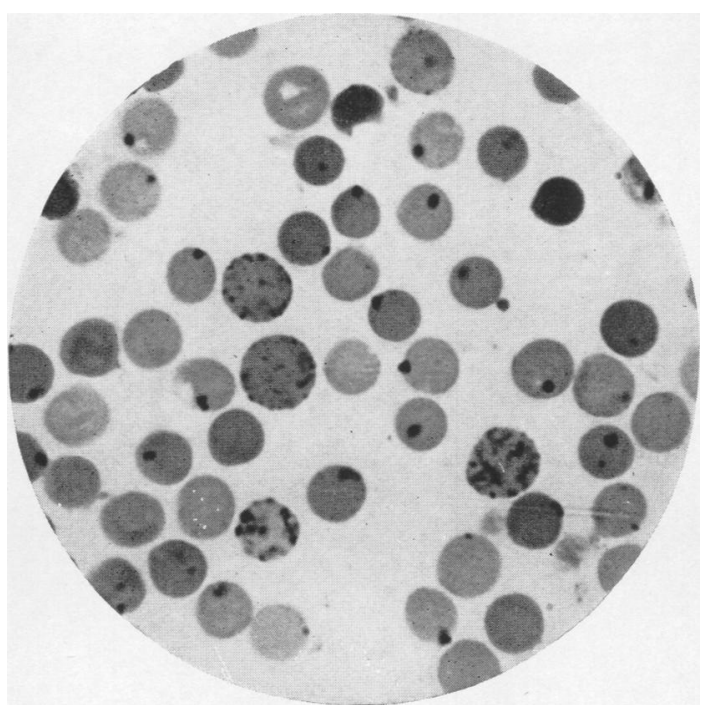

FIG. 2.-Heinz bodies and reticulocytes in Case 2 (brilliant cresyl blue supravital staining).

(1946-47) Heinz bodies appeared only after a second exposure to $m$-dinitrobenzene; from the graph presented by Jung it may be seen that methaemoglobinaemia in his case was also higher after the first exposure when no Heinz bodies were found. Thus, the assumption that Heinz bodies and methaemoglobinaemia are closely associated does not hold true in all cases. These clinical observations support the view of Heubner (1943) that the occurrence of Heinz bodies and methaemoglobinaemia are separate and independent phenomena. $m$-Dinitrobenzene, a toxic substance which is known to be a good producer of both phenomena, produced in one person both methaemoglobin and Heinz bodies but failed, under presumably identical circumstances, to produce the latter phenomenon in the other person.

Regarding the diagnostic significance of Heinz bodies, it has been repeatedly suggested (Schilling, 1932 : instruction of the German Government, 1941, quoted by Hughes and Treon, 1954 ; Gross, Bock, and Hellrung, 1942) that their determination might as an alternative test replace the more complicated estimation of methaemoglobin. Although the two isolated cases presented here furnish inadequate material from which to draw any general conclusions, it may easily be seen that one should not rely solely on the presence or absence of Heinz bodies for evaluation of the degree of toxic action of $m$-dinitrobenzene. A similar observation has recently been made by Hughes and Treon (1954): in three cases of poisoning due to "an aniline compound" they found both methaemoglobinaemia and Heinz bodies, while in the fourth " methaemoglobinaemia to the extent of $26.3 \%$ was found, but there were no Heinz bodies in the erythrocytes".

A moderate degree of anaemia was present in both cases with a slight difference in initial values for haemoglobin concentration and red cell count. However, as shown in Fig. 1, a steady rise in haemoglobin took place in Case 1, while first a fall then a rise was noted in Case 2. As evidenced also by the simultaneous rise of reticulocytes and by the serum iron values, an increased red cell turnover was more pronounced in Case 2. A rise in serum iron has also been observed in experimental intoxication in animals (Cammerer and others, 1949).

In the first case described here the liver was tender and enlarged ; the transient gastro-intestinal symptoms, including nausea and epigastric pain, might also be attributable to the lesion of the liver. It must be noted, however, that although the liver became progressively enlarged, the only abnormality, as shown by the liver function tests, was a slight and transient rise in serum bilirubin. Except for a similar slight increase of bilirubin in the blood of the second case there were neither clinical nor laboratory data which indicated liver damage.

Summarizing the main clinical features of the above cases, it is found that there was in Case 1 toxic methaemoglobinaemia with a moderate anaemia but without Heinz bodies in the erythrocytes ; enlargement of the liver with gastro-intestinal symptoms was in this case indicative of a liver injury. There was anaemia with Heinz bodies and no evidence of liver damage in Case 2. The unequal incidence of toxic symptoms under conditions of equal exposure in these cases points to the individual differences in response to the toxic action of $m$-dinitrobenzene.

\section{Summary}

Two cases of industrial $m$-dinitrobenzene poisoning in women are reported. The patients were engaged in the manufacture of $m$-dinitrobenzene ; the process and the potential hazards of the work are briefly described. The differences in clinical features, particularly in regard to the occurrence of Heinz bodies, methaemoglobinaemia, and liver damage are stressed and discussed.

My thanks are due to Dr. V. B. Vouk, Acting Director of the Institute of Industrial Hygiene, Yugoslav Academy of Sciences and Arts, for his help and friendly criticism. I am grateful also to Mr. A. Gerasimov, Photographic Laboratory, School of Public Health, University of Zagreb, for the photomicrograph. 


\section{REFERENCES}

Cammerer, A., Kiese, M., and Tauschwitz, K. (1949). Arch. exp. Path.

Pharmak., 206, 384.
Freifeld, H., Schilowa, A., and Ludwinowsky, R. (1937). Folia Haemat. (Lpz.), 56, 333 .

Gaede, D., and Kiese, M. (1949). Arch. exp. Path. Pharmak., 206, 569.

Glahn, M., and Schack-Schou, P. (1947). Nord. Med., 36, 2135.

Gross, E., Bock, M., and Hellrung, F. (1942). Arch. exp. Path. Pharmak., 200, 271.

Heilmeyer, L. (1943). Spectrophotometry in Medicine. Hilger, London. Heubner, W. (1943). Folia Haemat. (Lpz.), 67, 323

Huber, A. (1891). Virchows Arch. path. Anat., 126, 240.

Hughes, J. P., and Treon, J. F. (1954) Arch. industr. Hyg., 10, 192.

Jung, F. (1946-47). Klin. Wschr., 24-25, 459.

Kiese, M. (1949). Arch. exp. Path. Pharmak., 206, 361.

Kiese, M. (1949). Arch. exp. Path. Pharmak.

Koelsch, F. (1917). Zbl. Gew Hyg., 5, 60 .

-, (1954). Lehrbuch der Arbeitshygiene, p. 335. 3rd ed., Vol. I. Enke, Stuttgart.
Kunz, G. (1942). Arch. exp. Path. Pharmak., 199, 508.

Moeschlin, S. (1942). Folia Haemat. (Lpz.), 65, 345.

Monks, E. H. (1902). Lancet, 1, 89.

Nieden, A. (1888). Zbl. prakt. Augenheilk., 12, 193.

Oettingen, W. F. von (1941). Publ. Hlth Bull. (Wash.), No. 271

Rejsek, K. (1944). Cas. Lék. ces., 83, 1442.

Röhl, M. (1890). Dissertation. Rostock.

Ross, J. (1889). Med. Chron., 10, 89.

Runderlass des Reichsarbeitsministers und des Reichswirtschaftsministers, betr. Gesundheitschutz der Arbeiter in der Sprengstoffindustrie, (1941). Reichs-GesundhBl., 16, 372; quoted by Hughes, J. P., and Treon, J. F.

Schilling, V. (1932). Blut und Trauma. Fischer, Jena.

Schröder, C., and Strassmann, F. (1891). Vjschr. gerichtl. Med., 3 ser, 1, Suppl. p. 138

ser, 1, Suppl. p. 138.

Starkow, W. (1871). Virchows Arch. path. Anat., 52, 464

Starkow, W. (1871). Virchows Arch. path. Anat., 52,

White, R. Prosser (1889). Practitioner, 43, 14 ; quoted by Huber, A. (1891). 